\title{
NOTAS SOBRE LA FACULTAD DE AMPLIAR O RECTIFICAR LA DEMANDA UNA VEZ INICIADO EL JUICIO ORDINARIO.
}

\author{
JAIME ALCALDE SILVA ${ }^{1 *}$
}

\section{Resumen.}

El presente trabajo trata de precisar el sentido y alcance de la facultad de ampliar y rectificar la demanda que el artículo 261 CPC le concede al demandante una vez iniciado el juicio ordinario. Ella difiere de la posibilidad que admite el artículo $312 \mathrm{CC}$, donde se admite que cualquiera de las dos partes, en sus escritos de réplica o dúplica, pueda ampliar, adicionar o modificar las acciones y excepciones que ha formulado en su demanda o contestación, con tal de que esa alteración no afecte la controversia principal planteada ante el tribunal. Con apoyo del origen histórico de la regla y de una lectura sistemática dentro del contexto del Código de Procedimiento Civil, se trata de demostrar que la ampliación o rectificación de la demanda solo comprende el relato escrito presentado al tribunal y nunca cuando ya hubo un comportamiento del demandado que asume los términos materiales de la controversia judicial y traba la relación procesal. Por lo demás, esta posibilidad no se extiende a los procedimientos reformados, aunque sí viene recogida en el nuevo Código Procesal Civil con algunos cambios de en su formulación.

\section{Palabras clave:}

Juicio ordinario - ampliación de la demanda - Litispendencia.

\begin{abstract}
.
This paper tries to clarify the meaning and scope regarding the power to expand and rectify the civil complaint enlargement that Article 261

$1 \quad$ * Profesor asociado de Derecho Privado, Pontificia Universidad Católica de Chile. jcalcald@uc.cl
\end{abstract}


CPC grants to the plaintiff once the ordinary trial has begun. It differs from the possibility granted by Article $312 \mathrm{CC}$, which states that admitted that both parties two parties, in their reply or rejoinder briefs, may extend, add or modify the actions and exceptions that they have formulated in their demand or response, with the condition that this alteration does not affect the main controversy raised before the court. With the support of the historical origin of this rule and a systematic analysis considering the context of the Code of Civil Procedure, I will try to prove that the extension or rectification of the demand only includes the written account presented to the court and not when there was already a behavior of the defendant who assumes the material terms of the judicial controversy and locks the procedural relationship. Furthermore, this possibility does not extend to the reformed procedures, although it is included in the new Civil Procedure Code with some changes in its formulation

\section{Key words:}

General procedure - civil complaint enlargement - Litispendencia.

\section{Introducción.}

La práctica forense tiene aceptado que el demandante puede realizar cualquier modificación en su demanda con tal de que ella se produzca antes de la contestación, pues así lo permite el artículo 261 CPC. Dicha facultad viene refrendada asimismo por el artículo $312 \mathrm{CPC}$, que faculta a ambas partes para adicionar, ampliar o modificar sus acciones y excepciones en sus escritos de réplica y dúplica, siempre que ellas no alteren aquellas que sean el objeto principal del juicio. Sin embargo, esta interpretación no está exenta de dificultades por el tiempo que puede transcurrir entre que la demanda ha sido notificada al demandado y éste presenta su contestación. La razón es que previamente la demanda puede ser contradicha mediante la oposición de excepciones dilatorias, las cuales tardan en resolverse e incluso son susceptibles de posteriores recursos debido a que la sentencia que se pronuncia sobre ellas pone término al juicio.

Por el contrario, la tesis que aquí se pretende demostrar es que la ampliación de la demanda es extemporánea si se han opuesto excepciones dilatorias por parte del demandado o se ha realizado cualquier otro acto procesal que implique asumir la demanda como delimitación de la controversia planteada ante el tribunal, pues desde entonces la litis ya ha 
quedado trabada de manera definitiva bajo unos términos concretos de discusión. En otras palabras, esto significa que la expresión «contestación de la demanda» que emplea el artículo 261 CPC no está usada en el sentido técnico que le asigna el artículo 309 CPC, vale decir, no comporta el escrito donde se contienen las excepciones o defensas que el demandado opone a la demanda, sino que es sinónimo de cualquier comportamiento que fije irrevocablemente los contornos materiales de la discusión que se producirá durante el curso del proceso y que debe acabar con una sentencia del juez.

Por lo demás, conviene indagar si la línea interpretativa que aquí se sostiene resulta de utilidad para aquellos procedimientos reformados donde el Código de Procedimiento Civil opera de manera supletoria, como sí ocurre con el Proyecto de Código Procesal Civil presentado al Congreso a través del Mensaje núm. 004-360, de 12 de marzo de 2012 (Boletín núm. 8197-07), puesto que en él la facultad del actor de modificar la demanda se conserva con una redacción casi idéntica a la que hoy tiene en el artículo 261 CPC y con idénticos efectos.

La exposición comienza con la descripción del estado de la cuestión en torno a la facultad de ampliar la demanda en el juicio ordinario (II) y prosigue con la relectura propuesta y sus consecuencias (III). Enseguida se analiza qué ocurre con esta modificación en otros procedimientos (IV), para acabar con un cuerpo de conclusiones $(\mathrm{V})$.

\section{El estado de la cuestión.}

Para responder a la pregunta de hasta cuándo puede el demandante efectuar modificaciones a su demanda, la doctrina suele distinguir distintas situaciones conectadas con el grado de avance que haya tenido el juicio. ${ }^{2}$ Si la demanda todavía no ha sido notificada al demandado, el

2 Véase, por ejemplo, ANABALÓN SANDERSON, C.: El juicio ordinario de mayor cuantía. Editorial Jurídica de Chile, 1954, núm. 170-172, Santiago (Págs. 135-137) y 240-242 (Págs. 192-196); BENAVENTE GORROÑO, D.: Derecho procesal. Juicio ordinario y recursos procesales. $4^{\mathrm{a}}$ ed., actualizada por Juan Colombo Campbell. Editorial Jurídica de Chile, Santiago,1997. Pág. 19; BORDALÍ SALAMANCA, A./CORTEZ MATCOVICH, G./PALOMO VÉLEZ, D.: Procedimiento civil. El juicio ordinario de mayor cuantía. $5^{\text {a }}$ ed. Santiago, AbeledoPerrot/ThomsonReuters, Santiago, 2013. Págs. 116; CASARINO VITERBO, M.: Manual de Derecho procesal. Derecho procesal civil, IV. Editorial Jurídica de Chile, Santiago, 1997, núm. 331. Págs. 34-35; FIGUEROA YÁVAR, J. A./MORGADO SAN MARTÍN, E.: Procedimientos civiles e incidentes. LegalPublishing/ThomsonReuters, Santiago, 2013. Págs. 53-54; RODRÍGUEZ PAPIC, I.: Procedimiento civil. Juicio ordinario de mayor cuantía. $6^{a}$ ed. actualizada por Cristián Maturana Miquel. Editorial Jurídica de 
actor puede retirarla sin trámite alguno, y ella se considerada como no presentada para todos los efectos legales (artículo $148 \mathrm{CPC}$ ). Una vez reiterada ella materialmente por el demandante, puede hacer éste lo que estime conveniente y, por consiguiente, está facultado para presentar una nueva, completamente diferente de la anterior, con la que se dará inicio a otro juicio. Cuando la demanda ha sido notificada a cualquiera de los demandados y antes de la contestación, el demandante puede introducir las ampliaciones o rectificaciones que estime del caso (artículo 261 I CPC). Esas modificaciones se consideran como una nueva demanda, debiendo notificarse nuevamente a los demandados, y sólo desde que esa notificación se practique comienza a correr el término de emplazamiento (artículo 261 II CPC). Pero si la demanda ya ha sido contestada, el actor solo puede ampliar, adicionar o modificar las acciones que haya formulado en ella en la medida que esas variaciones no alteren las que han sido objeto principal del pleito, y el momento para hacerlo es el escrito de réplica (artículo 312 CPC). Por cierto, después de notificada la demanda, el demandante se puede desistir de ella en cualquier estado del juicio, pero su solicitud se tramitará como un incidente (artículo 148 CPC) y puede incluso ser rechazada si ha existido oposición (artículo 149 CPC). La sentencia que se pronuncie sobre este desistimiento trae consigo la extinción de las acciones a las que se refiera, con relación a las partes litigantes y a todas las personas a quienes habría afectado la sentencia del juicio a que se pone fin (artículo $151 \mathrm{CPC}$ ), como sucede con los terceros que hayan comparecido al juicio (artículo $24 \mathrm{CPC}$ ).

Esta facultad del actor para introducir cambios en su demanda se conserva en el Proyecto de Código Procesal Civil con una redacción casi coincidente a la que hoy tiene en el artículo 261 CPC y con idéntica eficacia: se ha de notificar de nuevo la demanda y su corrección, y solo desde entonces comienza a correr el término de emplazamiento. Fuera de los ajustes de estilo, la única novedad que conviene reseñar es que esta posibilidad recogida en el código actualmente vigente queda formulada de modo más general en el Proyecto, el cual la trata como un derecho a «modificar la demanda antes de que haya sido contestada» (artículo 257).

\section{La relectura propuesta.}

Chile, Santiago, 2003, núm. 14. Págs. 25-26; ROMERO SEGUEL, A.: Curso de Derecho procesal civil, III. ThomsonReuters, Santiago, 2015. Págs. 81-83. 
La relectura que enseguida se propone está destinada a demostrar que la ampliación de la demanda solo resulta posible en la medida que la relación procesal no se encuentra completamente trabada, lo cual ocurre cuando se verifica un supuesto complejo integrado por (i) la notificación de la demanda, (iii) el transcurso del término de emplazamiento y (iii) algún comportamiento procesal del demandado que dé lugar a la litispendencia (artículos 85, 257, 258, 259, 260, 305 y 309 CPC). ${ }^{3}$ De ahí que la expresión «contestación» que menciona el artículo 261 CPC para fijar el límite temporal que permite la ampliación o rectificación de una demanda no esté tomada según el sentido técnico que le asigna el artículo 309 CPC, sino que sea equivalente cualquier comportamiento procesal que adopta el demandado cuando le ha sido puesto en su conocimiento el libelo del actor, el cual se puede traducir en una serie de actos diversos, como contestar la demanda, allanarse a ella, negar total o parcialmente los hechos en que se sustenta la causa de pedir de la acción ejercida con él, apersonarse en el juicio realizando alguna actuación procesal distinta (por ejemplo, promoviendo un incidente de la nulidad de lo obrado hasta el momento), reconvenir, etcétera. El único requisito es que el comportamiento realizado por el demandado suponga la asunción de los términos de la demanda como base de su reacción procesal. De esto se sigue que «contestación» equivale a cualquier respuesta procesal de aquél, sin que ello suponga dotar la expresión del sentido específico que le asigna el artículo 309 CPC, vale decir, como el escrito que contiene las excepciones o defensas que el demandado opone a la demanda que contra él se dirige.

3 En ALCALDE SILVA, J.: «El saneamiento de la pequeña propiedad raíz. El sistema posesorio del Código Civil y el especial previsto por el DL 2695/1979. La interrupción civil de la prescripción. Momento a partir del cual se debe considerar que se ha producido el efecto interruptor de "todo recurso judicial". La notificación de la demanda como exigencia histórica y sistemática para que el dueño puede beneficiarse de dicha interrupción. Corte Suprema, sentencia de 31 de mayo de 2016 (rol núm. 6900-2015)». En: Revista Chilena de Derecho Privado, núm. 27, 2016. Págs. 263-270, se argumenta sobre la importancia que tiene la notificación de la demanda para que ella interrumpa la prescripción en un sistema como el chileno, que asigna a ese estado de pendencia un carácter perpetúo y no temporal, como ocurre en el derecho comparado. El artículo $8^{\circ}$ de la Ley 21.226, de 2 de abril de 2020, parece confirmar este aserto: la interrupción por la presentación de la demanda no está implícita en el Código Civil y resulta necesario que se acompañe de una carga de caducidad para el demandante (no cesar en la prosecución del juicio), como sucedía en el artículo 2503, núm. $2^{\circ}$ CC hasta la Ley 6162. La norma señala: «[...] se entenderá interrumpida la prescripción de las acciones por la sola presentación de la demanda, bajo condición de que esta no sea declarada inadmisible y que sea válidamente notificada dentro de los cincuenta días hábiles siguientes a la fecha del cese del referido estado de excepción constitucional [...] o dentro de los treinta días hábiles siguientes a la fecha en que la demanda fuere proveída, lo que suceda último». 
Que la modificación de la demanda sea imposible desde que ha transcurrido el término de emplazamiento y el demandado original ha realizado alguna actuación que suponga el reconocimiento de los términos materiales de la controversia dando lugar a la litispendencia proviene tanto de una razón histórica (1) como de la debida correspondencia sistemática de la figura en el contexto del proceso civil (2). Estas bases permiten diseccionar el texto del artículo 261 CPC para precisar cuál es el contenido de la facultad que ahí se confiere al demandante respecto de la demanda originalmente presentada (3).

\section{La historia legislativa del artículo $261 \mathrm{CPC}$.}

La primera pista sobre las razones que hay detrás de la regla del artículo 261 CPC se encuentra en el Mensaje fechado el $1^{\circ}$ de febrero de 1893 con el que el presidente Jorge Montt Álvarez presentó al Congreso Nacional para su discusión el proyecto del Código de Procedimiento Civil finalmente aprobado y promulgado a través de la Ley 1552, de 28 de agosto de $1902 .{ }^{4}$ El $§ 25$ de dicho Mensaje señala:

«[1] os procedimientos del juicio ordinario han recibido modificaciones de trascendental importancia, fijándose además en muchos [casos] las

$4 \quad$ Conviene recordar que la historia de la codificación procesal civil chilena se extiende desde 1852 hasta 1902, sin contar con los esfuerzos anteriores (1840, 1841 y 1845) para constituir comisiones de unificación de las leyes civiles y procesales que solo acabaron centradas en las primeras. Por Ley de 14 de septiembre de 1852 se facultó al presidente de la República para que encomendara la codificación de las leyes procesales civiles a una sola persona, recayendo ese nombramiento por decreto de 26 de octubre de ese año en Andrés Bello (1781-1865). Dado que Bello estuvo hasta 1856 encargado de preparar el Código Civil, poco pudo hacer para cumplir ese encargo, y esa fue la razón por la que el 15 de diciembre de ese año se nombró en su reemplazo a Antonio Varas (1817-1886). Sólo dos años después, este último hizo presente la imposibilidad de dar cumplimiento al encargo mientras no estuvieran previamente establecidas las bases de la organización judicial del país. Nada se había avanzado, entonces, hasta el comienzo de la década de 1860. A partir de ese momento se suceden cuatro proyectos: (i) el Proyecto primitivo, cuyo origen se encuentra en los trabajos de Francisco Vargas Fontecilla (1824-1883) y José Bernardo Lira (1835-1886); (ii) el Proyecto de 1884, fruto del trabajo de la primera Comisión (conocida como «Comisión Informante») que sesionó entre 1873 y 1884; (iii) el Proyecto de 1893, surgido de los trabajos de la segunda Comisión (llamada "Comisión Redactora») en funciones entre 1888 y 1892; (iv) el Proyecto de 1902, proveniente de la tercera Comisión (o «Comisión Mixta» por su composición) que sesionó entre 1900 y 1902. Véase CASARINO VITERBO, M.: Manual de Derecho procesal. Derecho procesal civil, III, $6^{\text {a }}$ ed. Actualizada. Editorial Jurídica de Chile, Santiago, 2005, núm. 5. Págs. 12-14 , y GUZMÁN BRITO, A., "La evolución jurídica", en SILVA VARGAS, F./VARGAS CARIOLA, J. E. (eds.), Historia de Chile, Vol. 2: La búsqueda de un orden republicano. 1826-1881, Santiago, Ediciones UC, 2019, $1^{\text {a }}$ parte, pp. 227-231.. 
reglas variables o de incierta aplicación aceptadas por la jurisprudencia de nuestros tribunales. Convenía precisar los casos en que es admisible la aplicación de la demanda, como asimismo dar reglas para el procedimiento de jactancia, sobre el cual nada determinado existe».

El texto transcrito muestra que la regla propuesta en el Proyecto de Código de Procedimiento Civil tenía por objetivo solucionar un problema propio de la práctica forense de aquel entonces, dado que en ella no estaban claros los supuestos en los cuales era admisible la ampliación de la demanda por parte del actor una vez iniciado el juicio. De ahí que resulte de particular interés la consideración de los antecedentes precodificados sobre el período de discusión del juicio ordinario y la historia del establecimiento del artículo $261 \mathrm{CPC}$, de manera de fijar la genuina extensión que se debe dar al sentido de esa norma (artículo 19 II CC). La razón proviene de que en este caso se está en presencia de un supuesto de interpretación restrictiva, dado que el sentido de la regla del mentado artículo 261 CPC es en realidad más acotado que el que parece sugerir su tenor literal. Esto exige acudir al «espíritu» de esa norma para saber cuál es su verdadero sentido, el cual se manifiesta en ella misma o en su historia legislativa (artículo 19 II CC).

Cumple advertir que la legislación procesal indiana era especialmente compleja y esa característica había originado el desarrollo de un género particular de obras jurídicas. ${ }^{5}$ Se trataba de comentarios y recopilaciones de los textos legales vigentes destinados a facilitar el trabajo de jueces y abogados a los que se añadía formularios de escritos y contratos de frecuente utilización. Por lo demás, este estado de confusión no era propio de la América española, sino que también ocurría en la Península. El conocido manual forense luego popularizado bajo el título de Febrero $^{6}$ en recuerdo de su primer autor puede servir para ilustrar la situación existente en el juicio ordinario del derecho castellano. De hecho, hasta la segunda

5 EYZAGUIRRE GUTIÉRREZ, J.: Historia del Derecho, $16^{\mathrm{a}}$ ed. Editorial Universitaria, Santiago, 2000. Pág. 213.

6 La obra es un curioso caso dentro de la ciencia jurídica. Publicada por primera vez en 1781 bajo el título de Librería de escribanos, ella se debe a José Febrero Bermúdez Osorio (1730-1790), quien carecía de titulaciones oficiales y no había seguido estudios universitarios formales. Su formación provenía de su tío sacerdote Juan Bermúdez, quien crió al joven en su natural Mondoñedo (Galicia) debido a que éste quedó huérfano prontamente, y del notario madrileño Gabriel Borgoñón, donde trabajó como escribiente. La Librería de escribanos es la única y monumental obra de este autodidacta jurista gallego, la cual fue ampliada y reeditada varias veces durante el siglo XIX con la intervención de Eugenio de Tapia, José Marcos Gutiérrez, Florencio García Goyena y Joaquín Aguirre, conservando como título principal el segundo nombre del autor con el que ella se hizo conocida en la práctica forense. 
mitad del siglo XIX era raro el despacho de abogados en España o en Hispanoamérica donde no hubiese alguna edición de esta obra. ${ }^{7}$ Respecto de la oportunidad procesal para ampliar la demanda, ahí se decía:

«También se acostumbra a poner en las demandas la siguiente protesta: "sobre lo cual pongo formalmente la demanda más arreglada y conforme a derecho, con la protesta de ampliarla, corregirla, suplirla y moderarla siempre y cuando convenga a mi parte, y con las demás que le sean útiles y conformes a justicia, que pido, etcétera”. Esta cláusula es muy útil para los efectos que menciona; pero sin embargo de ella, una vez contestado el pleito, no puede el actor sin consentimiento del reo, con quien casi contrae, apartarse de él, añadir ni enmendar la demanda en cosa sustancial, de modo que mude la acción a otra diversa, pues para ello es precisa nueva instancia o interpelación. Si la mutación o enmienda es de aquellas para las que no sólo no necesita el reo usar de nuevas excepciones y defensas, sino que antes bien se dirige a declarar la acción, o a moderarla, o ampliarla, o disminuir la cantidad pretendida en ella por las mismas causas y razones, pueden en virtud de dicha cláusula y no sin ella, así el demandante como su heredero o cesionario, hacerlo en la respuesta o réplica al pedimento de contestación del reo, y el juez debe sentenciar atendida la verdad, sin hacer mérito de las sutilezas de derecho. También lo pueden hacer después en el alegato de bien probado por lo justificado en la prueba con citación contraria (lo cual es corriente, y hemos visto practicar y practicado en pleitos que hemos seguido en esta corte), porque esto no muda la acción (ley 2, tít. 16, lib. 11, Novis. Recop.)». ${ }^{8}$

En Chile, el empleo de estos prontuarios o guías de tramitación de juicios fue también algo usual durante el siglo XIX, sobre todo porque, además de ser necesario establecer la ley aplicable y la doctrina, se requería conciliar éstas con la normativa que el país se iba dando como parte de su vida independiente. ${ }^{9}$ La primera recopilación que comenzó a ser utilizada con cierta asiduidad fue la Instrucción forense del abogado y profesor

$7 \quad$ BRAVO LIRA, B.: «El Derecho indiano después de la Independencia en América española: legislación y doctrina jurídica". En: Historia, núm. 19, 1984. Pág. 30.

8 GARCÍA GOYENA, F./AGUIRRE, J.: Febrero, o Librería de jueces, abogados y escribanos, VI, núm. 4541. I. Boix, Madrid, 1842. Pág. 4-5.

9 SALVAT MONGUILLOT, M.: «Sentido y forma de los prontuarios judiciales». En: Revista de Derecho Procesal. Núm. 7, 1974. Pág. 71, y «Los prontuarios jurídicos chilenos en la primera mitad del siglo XIX (estudio y bibliografía)». En: BibloteCA Del Congreso Nacional (ed.).: Homenaje a Guillermo Feliú Cruz, Editorial Andrés Bello, Santiago, 1973. Pág. 909. 
boliviano Francisco Gutiérrez de Escobar (1750-1805), la que acabó siendo conocida como el «Cuadernillo de Gutiérrez». Compuesta entre 1782 y 1791, se trataba de una obra destinada a los pasantes en práctica que el autor compuso, en su primera parte, como resultado de su labor docente; cuya segunda parte fue elaborada durante su vicepresidencia de la Academia Carolina de Práctica Forense, y que finalizó por incentivo de los alumnos y de varios amigos el mismo año de su designación como presidente de dicha institución. Como Charcas careció de imprenta durante el virreinato, se multiplicaron las copias manuscritas de la Instrucción forense, la cual también alcanzó influjo en otros lugares merced a los graduados extranjeros. Así, entre 1818 y 1842 el libro se publicó en cuatro sitios: Lima en 1818, Chuquisaca (Bolivia) en 1830, Santiago de Chile en 1832 y Quito en 1842. A este trabajo sucedió en influencia el Prontuario de los juicios (1844) redactado por Bernardino Vila García, quien cinco años después de su publicación llegaría a ocupar el cargo de fiscal de la Corte de Apelaciones de Valparaíso. Como fuere, el texto que gozó de mayor reputación fue el Prontuario de los juicios o Tratado de procedimientos juicios y administrativos con arreglo a la legislación chilena (1867) escrito por José Bernardo Lira Argomedo (1835-1886). ${ }^{10}$ Esta obra era casi un verdadero código procesal, pues contenía una útil ordenación de las variadas disposiciones de procedimiento vigentes, comenzando por las Partidas y autos acordados de la Real Audiencia y acabando con las «Leyes marianas» y los autos acordados de la Corte Suprema, cuya vigencia perduró hasta la entrada en vigor del Código de Procedimiento Civil el $1^{\circ}$ de enero de 1903. ${ }^{11}$ De hecho, su propio autor jugó un papel importante durante la codificación procesal civil, que se extendió durante buena parte de la segunda mitad del siglo XIX. ${ }^{12}$

En el Prontuario de los juicios escrito por Lira se trata de la ampliación de la demanda a propósito de las «otras cláusulas [otrosíes] que suelen ponerse en las demandas», algunas de las cuales «son útiles, otras completamente redundantes». ${ }^{13}$ Una de estas cláusulas consistía en «[1]a protesta de ampliar, enmendar o correjir la demanda», y sobre ella explica el autor, con cita de algunos fallos de la época:

10 BRAVO, «El Derecho indiano...», ob. cit. Pág. 33.

11 EYZAGUIRRE, Historia del Derecho, ob. cit. Pág. 213.

12 Véase las notas 3 y 14.

13 LIRA ARGOMEDO, J. B.: Prontuario de los juicios o Tratado de procedimientos juicios y administrativos con arreglo a la legislación chilena. $5^{\mathrm{a}}$ ed. Librería de Mariano Servat, Santiago,1895, I, núm. 286. Pág. 187. 
«No hai lei que exija esta reserva para conservar derechos que sin ella habrían de perderse. Por consiguiente, espresándola u omitiéndola, la situación del actor es siempre una misma: podrá o no alterar su demanda, según sean la naturaleza de la alteración i el estado del juicio. Antes de contestada la demanda puede modificarla sustancialmente i aun retirarla; pero en este último caso, si el reo lo pidiera, deberían resarcírsele los gastos que le hubiera ocasionado el emplazamiento i aun imponerse al actor perpetuo silencio sobre la acción deducida. Contestada la demanda, queda trabada la litis, es decir, formulado un combate judicial que debe decidirse por la sentencia del juez en favor de uno de los contendientes. Se supone entonces celebrado entre los litigantes un cuasicontrato del cual a ninguno es lícito separarse sin el consentimiento del otro. En tal estado no podría, pues, el actor variar ni retirar su demanda; pero se le admitirían lijeras alteraciones. Estas últimas, empero, para que puedan ser estimadas por el juez en la sentencia, deben formularse antes de rendida la prueba, porque solo así puede el reo utilizar respecto de ellas este medio que la lei concede a ambos litigantes para hacer triunfar sus pretensiones». ${ }^{14}$

Como se ve, existe coincidencia entre las explicaciones contenidas en estos formularios de juicios elaborados para España y Chile en cuanto al alcance de la ampliación, corrección o enmienda de la demanda. Esto significaba que, en las reglas aplicables al juicio ordinario antes de la entrada en vigor del Código de Procedimiento Civil, dicho acto procesal dependía de la magnitud que tenía la modificación que pretendía introducir el actor respecto de su demanda original. Contestada la demanda, y sin consentimiento del demandado, el demandante no podía efectuar modificaciones de tal envergadura que la controversia se alterase de manera sustancial, convirtiéndose la acción en otra diversa. Cuando solo se trata de correcciones accidentales, donde el demandado no necesitaba oponer nuevas excepciones o defensas, la ampliación estaba permitida siempre que se hiciese en el escrito de réplica y se hubiese introducido en la demanda la reserva de efectuar esa alteración. Pero incluso se admitía que la ampliación se efectuase en el alegato de bien probado (equivalente al escrito de observaciones a la prueba que menciona el artículo 430 CPC), siempre que se diese citación al demandado.

Pues bien, este era el panorama que el Proyecto de Código de Procedimiento Civil enviado por el presidente Jorge Montt al Senado quería clarificar. Sin embargo, dicho proyecto contenía una redacción del 
actual artículo 261 CPC mucho más amplia en cuanto a la oportunidad de la modificación de la demanda, pero con mayor precisión en cuanto a aquello que podía hacer el demandante por su intermedio. Decía el artículo 257 del Proyecto de 1893:

«Notificada la demanda a cualquiera de los demandados, sólo podrán hacerse en ella ampliaciones o rectificaciones que procedan de los mismos hechos en que la demanda se funde, sin modificar la acción deducida, y con tal que dichas modificaciones o rectificaciones se hagan antes de recibirse la causa a prueba, $\mathrm{o}$, si no hubiese lugar a este trámite, antes de la citación a las partes para sentencia definitiva».

Esta facultad de ampliación que se reconocía al actor suponía como contrapartida un derecho de defensa del demandado en los términos previstos por el artículo 258 del Proyecto de 1893, según el cual este último disponía de seis días para evacuar el traslado que había de conferírsele de toda ampliación o rectificación, garantizando así la bilateralidad de la audiencia.

La redacción final del artículo 261 (antes 258) CPC provino de la discusión habida en la sesión $13^{\circ}$ de la Comisión Mixta constituida en el Congreso para la revisión del Proyecto del Ejecutivo. ${ }^{15}$ Santiago Lazo Torrealba (1879-1940) resume del siguiente modo la discusión producida en esa sesión:

«El señor Riesco observó, respecto del primero [el artículo 257 del Proyecto de 1893], que debería darse mucha mayor amplitud al derecho de la parte [demandante] para ampliar la demanda antes de haberse contestado, no sólo por no existir litis trabada, sino porque en ese estado la ampliación no produce las perturbaciones que origina en el curso del pleito. El señor Bañados, por su parte, manifiesta que el traslado que debe

15 El Proyecto de Código de Procedimiento Civil presentado el $1^{\circ}$ de febrero de 1893 por el presidente Jorge Montt al Congreso Nacional es el resultado de la Comisión constituida por un decreto de 19 de marzo de 1888 para dar forma al Proyecto de Código de Enjuiciamiento Civil, el cual había sido entregado en 1884 por la comisión donde obraba como secretario de actas José Bernardo Lira. La discusión parlamentaria del proyecto se retrasó debido a las necesidades del país, que venía de concluir una cruenta guerra civil, por lo que se decidió crear una Comisión mixta se senadores y diputados, donde actúo como secretario Luis Barriga, para efectuar el estudio del proyecto. Esta comisión comenzó a sesionar el 10 de noviembre de 1900 y concluyó el 9 de enero de 1902. Cuatro días después se dio cuenta del informe de esta comisión y del proyecto en las cámaras, y este último fue sancionado a través de la Ley 1552, de 28 de agosto de 1902, para comenzar a regir el $1^{\circ}$ de marzo del año siguiente. Le Ley 3390, de 15 de julio de 1918, alteró la numeración del primitivo código, lo que explica el doble número de la mayoría de sus artículos. 
darse a toda ampliación [aquel del artículo 258 del Proyecto de 1893] sería innecesario cuando ella se produzca, por ejemplo, en el escrito de réplica del cual debe también conferirse traslado a la parte contraria. A indicación del señor Riesco se resolvió agregar en el título VII de este libro [aquel referido a «la contestación y los demás trámites hasta el estado de prueba o de sentencia»] una disposición [el actual artículo 312 CPC] análoga a la del artículo 548 del Código de Enjuiciamiento Civil de España [rectius: Ley de Enjuiciamiento Civil de 1881], que está más en armonía con las ideas enunciadas y reemplazar con arreglo a ella los artículos en estudio por el siguiente [sigue ahí la actual redacción del artículo $261 \mathrm{CPC}$ ]». ${ }^{16}$

Pues bien, la historia legislativa del artículo 261 CPC demuestra que la posibilidad de efectuar en la demanda ampliaciones y rectificaciones antes de la «contestación» por parte del demandado fue admitida por dos razones: (i) porque no se había trabado todavía la relación procesal y (ii) porque con ello no se originaban las perturbaciones que esto entraña durante la secuela del juicio, como ocurría con la situación por entonces existente. De ahí que la última oportunidad para hacer tales ampliaciones, adiciones o modificaciones sean los escritos de réplica o dúplica, pero sin que ello suponga una alteración de las acciones o excepciones que sean objeto principal del juicio (artículo $312 \mathrm{CPC}$ ), ${ }^{17}$ pues en adelante el período de discusión ha quedado definitivamente clausurado y lo que corresponde es demostrar mediante los medios correspondientes aquellos hechos sustanciales, pertinentes y controvertidos que se han mencionado durante la discusión (artículo $318 \mathrm{CPC}$ ). Asumida esta premisa, la cuestión estriba en fijar cuál es el sentido de la expresión "contestación de la demanda» que utiliza el artículo 261, la cual exige una lectura sistemática de esa regla dentro del contexto del Código de Procedimiento Civil.

\section{La lectura sistemática del artículo $261 \mathrm{CPC}$.}

16 LAZO TORREALBA, S.: Los códigos chilenos anotados. Código de Procedimiento Civil (conforme con la edición oficial reformada de 1918). Orígenes, concordancias, jurisprudencia. Poblete Cruzat Hnos., 1918, Santiago. Pág. 227.

17 La fuente del artículo 312 CPC es el artículo 548 de la Ley de Enjuiciamiento Civil española de 1881, el cual decía: «En los escritos de réplica y duplica, tanto el actor como el demandado fijarán concreta y definitivamente, en párrafos numerados, los puntos, de hecho $y$ de derecho objeto del debate, pudiendo modificar o adicionar los que hayan consignado en la demanda y contestación. También podrán ampliar, adicionar o modificar las pretensiones y excepciones que hayan formulado en la demanda y contestación, pero sin que puedan alterar las que sean objeto principal del pleito». 
El sentido del artículo 261 CPC que fluye de la historia fidedigna de su establecimiento (artículo 19 II CC) concuerda con la lectura de esa norma en el conjunto de disposiciones relativas al período de discusión del juicio ordinario, las cuales deben ser tomadas en cuenta porque las distintas partes de una ley han de tener entre sí la debida correspondencia y armonía (artículo $22 \mathrm{CC}$ ).

El propósito es demostrar que la expresión «contestación [de la demanda]» del artículo $261 \mathrm{CPC}$ no guarda exacta correspondencia con el acto procesal de ese nombre tratado en el artículo 309 CPC, pues ella alcanza también cualquier otro tipo de conducta que suponga una toma de posición del demandado respecto de la pretensión ejercida por el autor. La razón de que esto sea así es muy simple y se debe al estado de litispendencia, vale decir, al hecho de existir un juicio pendiente entre los mismos sujetos. ${ }^{18} \mathrm{El}$ derecho chileno parece haberse descantado por asignar al emplazamiento del demandando la virtud de dar comienzo a ese estado, lo que significa que, desde que se notifica la demanda y trascurre el término de emplazamiento previsto por la ley, la litis ha quedado definitivamente trabada (artículos 1911, 2503 y $2518 \mathrm{CC}$ ), con todos los efectos que son propios al estado de litispendencia (por ejemplo, el carácter litigioso de los derechos, la imposibilidad de retirar la demanda, la interrupción civil de la prescripción, la pérdida de la buena fe para las restituciones mutuas, etcétera). ${ }^{19}$

Cualquier interpretación contraria carece de sustento desde el punto de vista procesal, pues rompe con un principio fundamental al debido proceso como es la bilateralidad: quedaría al arbitrio del demandante modificar a su antojo la extensión de la litispendencia, con todos los efectos que ello supone, eliminando la función de garantía que ella entraña. ${ }^{20}$ Esto resulta especialmente relevante si se tiene en cuenta que los términos en el juicio ordinario son comunes y se cuentan desde la última resolución (artículo 260 CPC), pues es necesario que todos los demandados estén en un plano de igualdad de oportunidades en cuanto a su defensa y que las etapas del

18 ESCRICHE Y MARTÍN, J.: Diccionario razonado de legislación y jurisprudencia, nueva edición corregida por don Juan B. Guim. Librería de Rosa Bouret y Cía., París, 1852. Pág. 1191.

19 ROMERO, Curso de Derecho procesal civil, III, ob. cit. Págs. 81 y 125.

20 ROMERO, Curso de Derecho procesal civil, III, cit. Pág. 123, explica que la litispendencia dice relación con «el hecho de existir un juicio pendiente entre los mismos sujetos», la cual es precisamente una de las defensas que la ley permite interponer en el margen mismo del juicio (artículo 303, núm. $3^{\circ} \mathrm{CPC}$ ), para evitar la duplicidad de procesos. 
juicio se sucedan ordenadamente unas a otras para todos los que forman parte del proceso. ${ }^{21} \mathrm{Si}$ se modifica la demanda cuando ya ha habido reacción de parte de los demandados originales, eso trae aparejado que la cuestión controvertida se encuentra fijada y no se puede modificar, dado que la ritualidad del juicio ha comenzado a sucederse conforme a un cierto ritmo, el cual no se puede modificar unilateralmente.

Para concluir que la expresión «contestación de la demanda» del artículo 261 CPC no está tomada en un sentido técnico (aquel que le da el artículo 309 CPC), basta tener en cuenta que, desde el artículo 257 CPC en adelante, el referido código está pensando en el comportamiento procesal ideal (el Título I del Libro II trata sobre la demanda y sus consecuencias), que es precisamente la contestación de la demanda, porque en ella se oponen excepciones de fondo y se expresan de forma clara los hechos y fundamentos de derecho en que ellas se fundan (artículo 309 CPC), sin perjuicio de que en el término de emplazamiento se puedan realizar otros actos procesales por parte del demandado (por ejemplo, pedir la nulidad de la notificación, oponer excepciones dilatorias, reconvenir, etcétera). Esto significa que, si hay litispendencia, cualquier ampliación al objeto del proceso por el demandante se debe ajustar a los requisitos propios de la acumulación sobrevenida de acciones, de suerte que resulta necesario que se trate de dos o más procesos que hayan de constituir un solo juicio y fallarse por una sola sentencia (artículo 92 CPC), y siempre que ellos estén sometidos a una misma clase de procedimiento y se substancien en instancias análogas (artículo $95 \mathrm{CPC}$ ). ${ }^{22}$

Para demostrar esta limitación a la posibilidad de modificar la demanda, cumple revisar las distintas actitudes procesales del demandado una vez que se le notifica la demanda, como son la oposición de excepciones dilatorias (a), la rebeldía (b), el allanamiento (c) y la promoción de un incidente que asuma aquella como tal (d), y ver qué consecuencias trae consigo cada una de ellas dentro del proceso.

(a) La oposición de excepciones dilatorias.

Uno de los comportamientos posibles que puede adoptar el demandado una vez notificada la demanda es la oposición de excepciones dilatorias

21 ALCALDE SILVA, J.: «Sobre la eficacia procesal de la demanda que interrumpe la prescripción extintiva». En: Corral Talciani, H./Manterola Domínguez, P. (eds.): Estudios de Derecho civil XII. ThomsonReuters, , Santiago, 2017. Págs. 195-200.

22 ROMERO, Curso de Derecho procesal civil, III, ob. cit. Pág. 82. 
(artículo $305 \mathrm{CPC}$ ), las cuales se refieren «a la corrección del procedimiento sin afectar el fondo de la acción deducida» (artículo 303, núm. $6^{\circ} \mathrm{CPC}$ ). Cuando ésta ha sido su primera reacción procesal, eso significa que ha aceptado la controversia en los términos en que ella ha sido planteada por el demandante, pero previamente le exige que corrija ciertas cuestiones formales que se observan en el procedimiento y que cree indispensables para comenzar de manera correcta la discusión de fondo propiamente dicha. A partir de ese momento, la controversia ya ha quedado trabada entre las partes, porque el demandante asume las pretensiones contenidas en la demanda de acuerdo con los planteamientos de fondo con que ella fue propuesta, sólo que postergando la discusión hasta que ciertas cuestiones de forma sean previamente despejadas (artículo $308 \mathrm{CPC}$ ). De esto se sigue que, cuando tales excepciones se oponen, la cuestión controvertida no puede ser modificada por el demandante, y sólo caben las correcciones formales impuestas por la resolución que acoge esas excepciones (artículo $308 \mathrm{CPC}$ ), pues existe una relación procesal formada.

De lo contrario, y dado que la ampliación se considera una nueva demanda (artículo $261 \mathrm{CPC}$ ), la discusión podría nunca superar el estado procesal de oponer excepciones dilatorias, porque el demandante tendría la posibilidad de ampliar o corregir su demanda cuantas veces quisiera. De ahí que, por ejemplo, una antigua sentencia haya resuelto que, cuando la modificación de la demanda importa el abandono de las acciones entabladas o la alteración sustancial de ellas, se debe entender que el juicio queda circunscrito a aquélla, por no estar aún trabada la litis, ya que de otra forma tal alteración resultaría imposible. ${ }^{23}$

Por lo demás, si fuese posible ampliar la demanda después de opuestas las excepciones dilatorias por el demandado, se daría el absurdo de que ella no admite correcciones de forma en los términos del artículo $303 \mathrm{CPC}$, aunque tales errores existan, puesto que las excepciones dilatorias «deben oponerse [...] dentro del término de emplazamiento fijado por los artículos 258 a 260» (artículo 305 CPC), sin que haya mención al caso particular del artículo $261 \mathrm{CPC}$ que abre uno nuevo. Pero esto no se condice con que esa norma considere a la ampliación como una nueva demanda y, por tanto, que ordene computar de nuevo los plazos de emplazamiento desde la notificación de la ampliación. Cualquier interpretación en contrario no es aceptable porque conculca el derecho de defensa, ya que impide rectificar

$23 \quad$ Corte de Apelaciones de Santiago, sentencia de 3 de diciembre de 1903, Revista de Derecho y Jurisprudencia, tomo 1, 1903, sec. 2a, p. 197. 
las cuestiones de forma antes de entrar en la discusión de fondo del asunto controvertido. De hecho, si se acepta que el demandado pueda oponer nuevas excepciones dilatorias contra la demanda corregida, la situación es equivalente a la planteada precedentemente, y podría darse el caso de que el juicio nunca avance de esa etapa. Todos los actos procesales pensados como reacción del demandado frente a la demanda deben ser únicos, para evitar un desequilibro entre las posiciones de las partes.

(b) La rebeldía del demandado.

El Código de Procedimiento Civil no contempla el supuesto de reacción en que el demandado simplemente deja transcurrir el término de emplazamiento sin apersonarse en el juicio ni defenderse, salvo por la referencia que existe en el artículo 318 CPC a efectos de la recepción de la causa a prueba. El efecto general de la pasividad procesal viene previsto en el artículo 78 CPC para cualquier actuación del juicio, y consiste en que el trámite en cuestión se evacúa en rebeldía de dicha parte y el tribunal ha proveer lo que convenga para la prosecución del juicio. Pues bien, si se admite que la expresión "contestación de la demanda» del artículo 261 CPC tiene el sentido técnico que le confiere el mentado artículo 309 CPC, eso significaría que la facultad de ampliar o rectificar la demanda sería admisible en cualquier estado del juicio, hasta la citación para oír sentencia (artículos 432 y $433 \mathrm{CPC}$ ), cuando aquel se ha seguido en rebeldía del demandado, pues entonces no hay propiamente «contestación de la demanda» y solo existe la preclusión de su derecho a defenderse de manera expresa (artículo $78 \mathrm{CPC}$ ). ${ }^{24}$ Sin embargo, la rebeldía del demandado denota una negación de la pretensión ejercida, poniendo de cargo del demandante acreditar sus afirmaciones, ${ }^{25}$ por lo que, desde que se ha evacuado el trámite de la contestación dando traslado al actor para replicar (artículo $311 \mathrm{CPC}$ ), ya no resulta posible la alteración de la demanda, salvo que se trate de ampliar, adicionar o modificar las acciones ejercidas que no impliquen un cambio respecto de aquellas que son objeto principal del juicio (artículo 312 CPC) ${ }^{26}$ De hecho, este comportamiento procesal se denomina también

24

GANDULFO RAMÍREZ, E.: «Sobre preclusiones procesales en el Derecho chileno en tiempo de reformas. Ensayo de una teoría general desde un enfoque valorativo jurídico». En: Revista Ius et Praxis, vol. 15, núm. 1, 2009. Pág. 131.

25 ANABALÓN, El juicio ordinario, ob. cit., núm. 217. Pág. 175.

26 La facultad del artículo 312 CPC parece estar formulada en términos de accesoriedad, de manera que la ampliación, adición o modificación de las acciones y excepciones solo se puede hacer en la medida que haya existido contestación expresa del demandado. Por eso, la 
«contestación ficta de la demanda». ${ }^{27}$ Por cierto, este sentido que se asigna a la rebeldía del demandado se basa en dos supuestos: (i) que la demanda le haya sido notificada legalmente (artículos 40 y 44 CPC), puesto que en caso contrario se puede deshacer lo obrado si aquel logra demostrar que, por un hecho que no le sea imputable, han dejado de llegar a sus manos las copias de la demanda y de su proveído o que ellas no son exactas en su parte substancial (artículo $80 \mathrm{CPC}$ ); y (ii) que el demandado tenga la posibilidad efectiva de comparecer al juicio, de suerte que puede rescindir todo lo obrado en su rebeldía cuando ha estado impedido de actuar por fuerza mayor (artículo $79 \mathrm{CPC}$ ).

(c) El allanamiento.

Hay allanamiento cuando el demandado acepta completamente las pretensiones que el demandante ha ejercido en su demanda (artículo 313 $\mathrm{CPC}$ ), lo cual puede ocurrir de manera expresa o tácita. El allanamiento es expreso cuando el demandado reconoce categóricamente los hechos y el derecho invocado en la demanda, y tácito, cuando deposita la cosa o ejecuta el hecho que se reclama. ${ }^{28}$ Esto significa que solo en el primer caso existe un acto procesal que se materializa en un escrito dotado de contenido propio, puesto que en el segundo lo relevante es la finalidad del comportamiento adoptado, que puede carecer de correspondencia en el proceso. Cuando así ocurre, la situación es distinta a la rebeldía del demandado, puesto que el juicio debe proseguir con el traslado para la réplica del demandante (artículo $311 \mathrm{CPC}$ ) y, con ella, se citará a las partes para oír sentencia (artículo 313 CPC). En la sentencia definitiva, el tribunal deberá ponderar, de acuerdo con lo aseverado en la demanda y la prueba documental acompañada a ella (artículo $255 \mathrm{CPC}$ ), la procedencia de la decisión que ha solicitado el demandante (artículos 160 y 170 CPC). Por su parte, el allanamiento tácito presenta algunas dificultades en cuanto a su reconocimiento por el tribunal, dado que el demandante deberá pedir que éste asigne el carácter de tal al comportamiento del demandado, ordenando la prosecución del juicio según lo dispuesto en el artículo 313 CPC, sin

aplicación de esa regla no resulta posible cuando ha existido allanamiento del demandado, en cuyo caso corresponde aplicar el artículo 313 CPC y, evacuada la réplica del demandante, citar a las partes para oír sentencia.

27 RODRÍGUEZ, Procedimiento civil, ob. cit., núm. 54. Pág. 73.

28 RODRÍGUEZ, Procedimiento civil, ob. cit., núm. 55. Pág. 75. 
perjuicio de la posibilidad de aquél de solicitar esa declaración para evitar una doble condena respecto de un hecho que ya ha ocurrido.

El tratamiento dispensado al allanamiento expreso hace imposible que el demandante pueda ampliar la demanda en los términos del artículo 261 $\mathrm{CPC}$, puesto que ha habido un acto procesal al que la ley le otorga valor expeditivo equivalente a la contestación del artículo 309 CPC. La única posibilidad de modificación es aquella que concede el artículo $312 \mathrm{CC}$, de suerte que en su escrito de réplica el demandante podrá ampliar, adicionar o modificar las acciones que haya formulado en la demanda, sin alterar la que es objeto principal del juicio. Debido a que el actor no puede alterar la controversia que el tribunal debe resolver, parece que esta modificación no tiene magnitud suficiente para desplazar la regla del artículo 313 CPC, por lo que aquél habrá de citar a las partes sin más trámites, sin conceder traslado para replicar. La razón es que el allanamiento se caracteriza por el reconocimiento por parte del demandado de la legitimidad de la pretensión ejercida por el actor, sin importar que haya divergencias en cuanto a los hechos que la sustentan (artículo 313 CPC).

(d) La promoción de un incidente que asuma la demanda como tal.

Queda por revisar el caso en que el demandado comparece en el juicio dentro del término de emplazamiento, pero no opone excepciones dilatorias, contesta la demanda o se allana a ella. Por el contrario, su actuación se traduce en la promoción de un incidente de previo y especial pronunciamiento (artículo 84 II CPC). Descartando los casos en que el incidente que se promueve rechaza el juicio en los términos en que ha sido iniciado por la demanda, como ocurre cuando se solicita la declaración de nulidad por incompetencia absoluta del tribunal (artículos 83 II CPC) ${ }^{29}$ cabe asumir que este acto procesal tiene la virtud de aceptar los términos materiales de la controversia (artículo 84 II CPC). Por eso, la promoción extemporánea de esta clase de incidentes debe ser rechazada de oficio por el tribunal, salvo que se trate de una nulidad o de una circunstancia esencial

29 Por ejemplo, la nulidad fundada en que la controversia se debía someter a arbitraje o a una jurisdicción diferente. Por lo demás, cabe tener en cuenta que los elementos que determinan la competencia absoluta son complejos y los parámetros usualmente mencionados (persona o fuero, materia y cuantía) resultan insuficientes para explicar la manera en que se distribuye la competencia. Véase SÁEZ MARTÍN, J.: «Los elementos de la competencia jurisdiccional». En: Revista de Derecho de la Universidad Católica del Norte, vol. 22, núm.1, 2015. Págs. 529-570. 
para la ritualidad o la marcha del juicio, pues entonces aquél ordenará que se practiquen las diligencias necesarias para que el proceso siga su curso legal (artículo 84 II CPC). ${ }^{30}$ El ejemplo más característico de esta situación en que se aceptan los términos de la controversia es la nulidad de la notificación de la demanda, sea por defectos en la forma de efectuarla, ${ }^{31}$ el domicilio en que se practica, ${ }^{32} \mathrm{o}$ la persona a quien se ha dirigido, ${ }^{33}$ puesto que en todos ellos el demandado discute el modo en que se ha tramitado el juicio, sin incidir sobre la pretensión ejercida. En estos casos, tampoco resulta posible la modificación de la demanda en los términos previstos en el artículo $261 \mathrm{CPC}$, puesto que la relación procesal ya ha quedado formada y solo existe un impedimento formal o de procedimiento que posterga el inicio de la discusión. La situación es, entonces, muy parecida a la que se produce con las excepciones dilatorias.

\section{El contenido del artículo $261 \mathrm{CPC}$.}

Hecha la relectura precedente sobre el límite temporal a la facultad concedida al actor en el artículo 261 CPC, cumple analizar cuál es el contenido que ella tiene. Si se lee con detención, esta regla permite efectuar dos acciones relacionadas con la demanda, vale decir, con el relato argumental hecho por el demandante al ejercer su pretensión y recogido en un escrito presentado ante el tribunal (a), como son la posibilidad de ampliarla (b) o de modificarla (c).

(a) La modificación recae sobre la demanda y no sobre las acciones ejercidas.

30 El problema estribará, entonces, en una cuestión de plazos, ya que la nulidad solo se podrá impetrar a petición de parte dentro de los cinco días siguientes a que aparezca o se acredite que quien reclama de la nulidad tuvo conocimiento del vicio, salvo que se trate de la incompetencia absoluta del tribunal (artículo 84 II CPC).

31 Por ejemplo, si el receptor no encuentra nadie en el domicilio del demandado, o si por cualquiera otra causa no es posible entregar dichas copias a las personas que se encuentren en esos lugares, y en vez de fijar en la puerta un aviso que dé noticia de la demanda, con especificación exacta de las partes, materia de la

causa, juez que conoce en ella y de las resoluciones que se notificaciones (artículo 44 II CPC), las deja con un vecino.

32 Por ejemplo, si se notifica la demanda contra una sociedad en el domicilio en que ella tiene su casa matriz, pese a que el contrato lo suscribió o el hecho lo ejecutó una de sus sucursales situada en otro lugar (artículo 142 COT).

33 Por ejemplo, cuando una demanda se notifica al presidente del directorio de una sociedad anónima, y no a su gerente general (artículos 39, 40 y 49 LSA). 
Aunque parezca algo evidente, la modificación que el artículo 261 CPC permite efectuar al actor recae sobre la demanda que ha presentado y sobre no la acción ejercida, y siempre que ello no importe alterar aquellas acciones que constituyen el objeto principal del pleito (artículo $312 \mathrm{CPC}$ ). Esta distinción no es superflua y encuentra apoyo en la distinta redacción que tienen los artículos 261 y $312 \mathrm{CPC}$, ambos referidos al ejercicio de este derecho de corrección en etapas distintas del juicio. La primera de esas normas señala que el demandante puede hacer en la demanda «las ampliaciones y rectificaciones que estime convenientes» antes de que sea contestada (artículo $261 \mathrm{CPC}$ ), mientras que la segundo dispone que «[e] $n$ los escritos de réplica y dúplica podrán las partes ampliar, adicionar o modificar las acciones y excepciones que se hayan formulado en la demanda y contestación» (artículo $312 \mathrm{CPC}$ ). Como se ve, aquello que se puede ampliar o modificar por el demandante es distinto en cada caso. En el primer supuesto, esas enmiendas recaen sobre la demanda, vale decir, sobre el escrito con el que normalmente se inicia un juicio (artículo 253 CPC) y en el que, exponiendo los hechos y los fundamentos de derecho que se crean aplicables, se solicita del juez un pronunciamiento favorable a una determinada pretensión (artículos $254 \mathrm{CPC}$ ) ${ }^{34}$ En el segundo caso, en cambio, las ampliaciones o modificaciones recaen sobre las acciones $\mathrm{y}$ excepciones que las partes han ejercido $\mathrm{u}$ opuesto en sus respectivos escritos de demanda (artículo 254 CPC) y contestación (artículo 309 CPC), con la restricción de que ellas pueden alterar las que sean objeto principal del pleito porque tales son las que soportan la relación procesal.

Un ejemplo tomado de la jurisprudencia puede ayudar a comprender esta diferencia. La Corte Suprema falló que, si se adiciona la demanda con una acción distinta de la formulada en ella, haciéndola valer en forma subsidiaria, se vulnera la regla del artículo 312 CPC.${ }^{35}$ En la especie se trataba de las acciones contempladas en los artículos 898 y $900 \mathrm{CC}$, cuya finalidad es diversa: la primera se dirige a obtener la restitución del precio en que se enajenó la cosa; en cambio, la segunda busca la devolución de la cosa misma o su valor, considerando, en este último caso, al poseedor como de mala fe. ${ }^{36}$ Dado que las acciones difieren en cuanto a su objeto,

34 MUÑOZ MACHADO, S. (dir.): Diccionario panhispánico del español jurídico. Santillana, Barcelona, 2017, I. Pág. 755.

35 Corte Suprema, sentencia de 19 de marzo de 1986, Fallos del Mes, núm. 328, 1986 , sent. $6^{\mathrm{a}}$, p. 16 (considerando $1^{\mathrm{o}}$, p. 16 ).

36 Véase ALCALDE SILVA, J.: «Las "acciones de dominio" del artículo 898 del Código Civil». En: Gómez de la Torre, M./Hernández Paulsen, G./Lathrop Gómez, F./Tapia 
adicionar una acción a la otra significa alterar el objeto principal del pleito que quedó fijado con la demanda y su contestación.

(b) La ampliación de la demanda.

La primera acción que el artículo 261 CPC permite al actor es la ampliación de su demanda, lo cual significa extenderla a puntos no comprendidos originalmente en ella. Puede el demandante, entonces, dar un mayor desarrollo a la pretensión que ha ejercido y también extender ésta a otras cuestiones o prestaciones accesorias, sin que varíe su naturaleza ni los fundamentos en que ella se sustenta. ${ }^{37}$ El límite a esta facultad vendrá dado por los contornos de la acción ejercida, vale decir, no se puede alterar los sujetos, la cosa pedida y la causa de pedir de la acción que constituye la materia principal de la controversia promovida ante el juez, pero sí agregar hechos o circunstancias o añadir los reajustes o intereses que en su inicio se omitieron. Esto significa, por ejemplo, que no es posible agregar un nuevo demandante o un nuevo demandado, ni tampoco ejercer una nueva acción (incluso si ésta es de la misma clase que aquella originalmente expuesta en la demanda), salvo cuando el caso emane directamente e inmediatamente de los mismos hechos (artículo 18 CPC).

(c) La rectificación de la demanda.

La segunda acción que el actor puede realizar de acuerdo con el artículo 261 CPC es rectificar la demanda, y esto ocurre cuando se modifica la opinión que se había expuesto en su texto original o se corrigen las imperfecciones, errores o defectos que éste contenga. De hecho, ese es el comportamiento que se exige al demandante cuando se acogen las excepciones dilatorias que ha opuesto el demandado, todas las cuales apuntan a la corrección del procedimiento (artículo 303, núm. $6^{\circ} \mathrm{CPC}$ ): debe subsanar los defectos que adolecía su demanda, para que el demandado la conteste dentro del término de diez días (artículo $308 \mathrm{CPC}$ ). Por consiguiente, antes de que el demandado ejecute un acto procesal que supone asumir la demanda como tal, el demandante puede enmendar, corregir o rectificar los fundamentos fácticos y jurídicos de la pretensión ejercida, pero manteniendo inalterados

Rodríguez, M. (eds.): Estudios de Derecho civil XIV. ThomsonReuters, Santiago, 2019. Págs. 267-300. 
los elementos de su acción (sujetos, cosa pedida y causa de pedir). ${ }^{38}$ Esto significa, por ejemplo, que la rectificación de la demanda no podría encubrir un desistimiento parcial de la acción ejercida, puesto que eso significaría el uso de esta facultad en fraude de ley con el fin de evadir las limitaciones de los artículos 148, 149 y 150 CPC.

\section{La ampliación de la demanda en otros procedimientos.}

Para acabar, queda revisar la aplicación de la facultad de ampliar la demanda en aquellos juicios que permiten la aplicación subsidiaria del Código de Procedimiento Civil. Es el caso del juicio ordinario de familia (1), del trabajo (2) y de policía local (3). Por el contrario, no cabe admitir dicha ampliación en los juicios que tienen un procedimiento específicamente determinado por la ley, como sucede con el juicio sumario (artículos $3^{\circ} \mathrm{y}$ $683 \mathrm{CPC}$ ) o el juicio especial establecido para los arrendamientos de bienes raíces urbanos (artículo $8^{\circ}$ de la Ley 18.101).

1. La ampliación de la demanda en los juicios de familia.

En la Ley 19.968, que regula los tribunales de familia y los procedimientos seguidos ante ellos, no existe mención a la facultad del demandante para hacer ampliaciones o rectificaciones en su demanda antes de que ella sea contestada por el demandado. Simplemente se dice que el juicio comienza por demanda escrita (artículo 56 de la Ley 19.968), la cual debe ser notificada al demandado con al menos quince días de antelación a la celebración de la audiencia preparatoria (artículo 59 II de la Ley 19.968). Por su parte, el demandado debe contestar la demanda hasta cinco días antes de la realización de esa audiencia (artículo 58 de la Leu 19.968). La aplicación subsidiaria del Código de Procedimiento Civil prevista por el artículo 27 de la Ley 19.968 sólo renvía a las disposiciones comunes a todo procedimiento (Libro I), y siempre que ellas no resulten incompatibles con la naturaleza de los procedimientos que dicha ley establece, de suerte que el artículo 261 CPC no recibe aplicación por formar parte del Libro III de ese código. ${ }^{39} \mathrm{~A}$ la misma conclusión se puede llegar por aplicación de los principios de oralidad, concentración e inmediación (artículos $9^{\circ}, 10,11 \mathrm{y}$ 12 de la Ley 19.968), como se verá enseguida.

$38 \quad$ ANABALÓN, El juicio ordinario, ob. cit., núm. 241. Pág. 194.

39 GANDULFO, «Sobre las preclusiones procesales...», ob. cit. Pág. 186, estima que la modificación sí es procedente hasta que el demandado presente su contestación. 
2. La ampliación de la demanda en los juicios laborales.

Algo parecido ocurre con el Código del Trabajo, que tampoco contiene ninguna referencia a la facultad del demandante de ampliar la demanda en el tiempo intermedio entre su presentación y la contestación del demandado, la cual debe producirse al menos con cinco días de antelación a la celebración de la audiencia preparatoria (artículo 452). A su vez, entre la notificación de la demanda y dicha audiencia ha de mediar un término no menor a quince días (artículo 451 del Código del Trabajo). Esto significa que, en principio, cabe aplicar la regla del artículo 432 del Código del Trabajo, que remite supletoriamente a las normas contenidas en los Libros I y II del Código de Procedimiento Civil, a menos que ellas sean contrarias a los principios que informan el procedimiento laboral. Pues bien, el artículo 261 CPC integra el Libro II de ese código, por lo que forma parte de las normas a las que reenvía la legislación laboral. ${ }^{40} \mathrm{Sin}$ embargo, la consideración de los principios formativos del procedimiento lleva a concluir que no cabe la ampliación de la demanda en los juicios laborales aun cuando materialmente exista oportunidad de hacerlo. La razón es que en ellos rige el principio de concentración (artículo 425 I del Código del Trabajo), el cual exige que se desarrolle la máxima actividad procesal dentro de las audiencias o en el menor número posible de éstas (artículo 428 del Código del Trabajo). A esto se agrega que, salvo que la ley disponga lo contrario, las actuaciones en el juicio son orales (artículo 425 II del Código del Trabajo) y, por consiguiente, son las audiencias preparatorias o de juicio los momentos idóneos para que ocurran, porque en ellas está presente el juez (artículo 425 I del Código del Trabajo).

\section{La ampliación de la demanda en los juicios de policía local.}

Tampoco parece que la ampliación de la demanda tenga cabida en los procedimientos seguidos ante los juzgados de policía local, respecto de los cuales la Ley 18.287 no remite de manera supletoria el Código de Procedimiento Civil. De igual forma, el procedimiento tiene una estructura concentrada que excluye mayores dilaciones. La demanda debe ser notificada al demandado con el fin de que concurra a la audiencia de contestación y prueba que fije el tribunal (artículos $7^{\circ}$ y $8^{\circ}$ de la Ley 18.287). En el caso de la demanda civil derivada de accidentes del tránsito, 
ella ha de ser presentada con tres días de anticipación a la realización del comparendo de contestación y prueba (artículo $9^{\circ}$ II de la Ley 18.287), lo que lleva a pensar que tampoco ahí es posible la modificación.

\section{La ampliación de la demanda en el Proyecto de Código Procesal Civil.}

La interpretación que aquí se ha propuesto es consistente con el tratamiento de la facultad de modificar la demanda que recoge el Proyecto de Código Procesal Civil. Ella puede hacerse hasta que el demandado la haya contestado (artículo 257), lo cual ocurre tanto cuando hay rebeldía (artículo 264) como cuando se allana total o parcialmente a la demanda, opone excepciones previas o contesta derechamente la demanda (artículo 265). La particularidad es que las excepciones previas se oponen en el mismo escrito de contestación (artículo 267), debiendo el actor evacuar el traslado en la audiencia preliminar y sujetándose su tramitación a la prevista para los incidentes (artículos 268). De ahí que se prohíba a las partes alterar el contenido de la demanda, la contestación y, en su caso, la reconvención (artículo 276 I), salvo a favor del actor en el tiempo intermedio entre la presentación de su demanda y la contestación del demandado (artículo 257). De modo similar a como actualmente se prevé para los escritos de réplica y dúplica en el artículo 312 CPC, el Proyecto concede que las partes puedan efectuar en la audiencia preliminar las alegaciones que estimen procedentes respecto de lo expuesto por la contraria, con el fin de aclarar o modificar las pretensiones o defensas formuladas, pero sin que ellas puedan alterar sustancialmente las que sean objeto principal del pleito (artículo 276 II). Como fuere, la mayor novedad que añade el Proyecto en esta materia dice relación con la alegación de hechos nuevos. Esta facultad consiste en que, si con posterioridad a la notificación de la demanda o después de la contestación a la misma o de la reconvención, ha ocurrido algún hecho nuevo que sea de relevancia para fundamentar las pretensiones o defensas de las partes y la decisión sobre el asunto controvertido, o hubiese llegado noticia de un hecho relevante para la decisión que la parte no haya podido ni debido conocer con anterioridad, las partes podrán alegarlo durante el curso del proceso por escrito o a más tardar en la audiencia preliminar, ofreciendo la prueba necesaria para acreditarlo (artículo 276 III). 


\section{Conclusiones.}

Una práctica forense respaldada por la doctrina acepta que el actor pueda ampliar o modificar la demanda hasta que el demandado haya contestado la demanda, asumiendo que ese acto solo tiene lugar cuando se presenta el escrito que contiene las excepciones que aquél opone a la demanda y la exposición clara de los hechos y fundamentos de derecho en que se apoyan. Esto significa que la oposición de excepciones dilatorias o la promoción de incidente que no desconozca la demanda en cuanto tal no comporta un obstáculo para el ejercicio de dicha facultad del demandante. Sin embargo, esta comprensión no es consistente con la historia legislativa del artículo 261 CPC ni con su lectura sistemática dentro del código del que forma parte, puesto que la norma contiene un caso de interpretación restrictiva. Esto quiere decir que su sentido es en realidad más reducido que el que se desprende de su tenor literal.

Bien mirado el problema, el límite a la facultad de modificar la demanda se encuentra en el efecto que produce la formación de la relación procesal, dando lugar al estado de litispendencia. Éste impide que la delimitación material de la controversia pueda ser alterada unilateralmente por el demandante, puesto que el demandado ya ha comparecido y aceptado los términos en que aquél ha planteado el asunto cuya decisión solicita al tribunal. La principal objeción contra este planteamiento es que la modificación de la demanda no vulnera el derecho de defensa del demandado, puesto que ella se considera como una nueva demanda para efectos de su notificación y éste puede formular sus descargos en la oportunidad correspondiente. Aceptar esta lectura, que parece consistente desde un punto de vista general, presenta otras dificultades más profundas. La primera de ellas es que rompe el principio que exige que los actos procesales sean unitarios, para garantizar la prosecución del juicio. Si fuese posible que el demandante modificase la demanda hasta la contestación, excluyendo la oposición de las excepciones dilatorias o de un incidente que no implique desconocer aquélla, eso significa que el juicio podría no superar el estado de corrección formal de la demanda, puesto que, por consistencia, hay que aceptar que el hecho de reputarse la modificación una nueva demanda entraña que contra ella se pueden oponer otras excepciones dilatorias, con el solo límite de aquellas que ya se opusieron o que, habiendo podido oponerse, no lo fueron. Un segundo inconveniente dice relación con la instrumentalización del proceso $\mathrm{y}$, sobre todo, con la posibilidad de servirse de este expediente para conseguir finalidades no previstas en 
el espíritu de la regla, como la agregación de otras partes (demandantes o demandados) o de una nueva cosa pedida. De igual manera, asignar al término «contestación de la demanda» un sentido comprensivo de cualquier comportamiento del demandado que dé lugar a la relación procesal permite que el allanamiento o la rebeldía del demandado tengan una consecuencia equivalente con las otras conductas posibles.

Por lo demás, esta forma de entender el artículo 261 CPC cuadra con los procedimientos reformados, donde la concentración que rige el proceso parece justificar la ausencia de una regla de esta naturaleza (como sucede respecto del juicio ante los juzgados de familia o del trabajo), y sirve para el análisis que habrá de hacerse, si se aprueba, del Proyecto de Código Procesal Civil, donde la facultad viene recogida como un derecho del demandante en términos casi idénticos a los que hoy tiene.

\section{Bibliografía}

ALCALDE SILVA, J.: «El saneamiento de la pequeña propiedad raíz. El sistema posesorio del Código Civil y el especial previsto por el DL 2695/1979. La interrupción civil de la prescripción. Momento a partir del cual se debe considerar que se ha producido el efecto interruptor de "todo recurso judicial". La notificación de la demanda como exigencia histórica y sistemática para que el dueño puede beneficiarse de dicha interrupción. Corte Suprema, sentencia de 31 de mayo de 2016 (rol núm. 6900-2015)». En: Revista Chilena de Derecho Privado, núm. 27, 2016. Págs. 249-273.

ALCALDE SILVA, J.: «Las "acciones de dominio" del artículo 898 del Código Civil». En: Gómez de la Torre, M./Hernández Paulsen, G./Lathrop Gómez, F./Tapia Rodríguez, M. (eds.): Estudios de Derecho civil XIV, ThomsonReuters, Santiago, 2019. Págs. 267-300.

ALCALDE SILVA, J.: «Sobre la eficacia procesal de la demanda que interrumpe la prescripción extintiva». En: Corral Talciani, H./Manterola Domínguez, P. (eds.): Estudios de Derecho civil XII, , ThomsonReuters, Santiago 2017. Págs. 189-209.

ANABALÓN SANDERSON, C.: El juicio ordinario de mayor cuantía. Editorial Jurídica de Chile, Santiago, 1954. 
BENAVENTE GORROÑO, D.: Derecho procesal. Juicio ordinario y recursos procesales. $4^{\mathrm{a}}$ ed. actualizada por Juan Colombo Campbell. Editorial Jurídica de Chile, Santiago, 1997.

BORDALÍ SALAMANCA, A./CORTEZ MATCOVICH, G./PALOMO VÉLEZ, D.: Procedimiento civil. El juicio ordinario de mayor cuantía. AbeledoPerrot/ThomsonReuters, Santiago, 2013.

BRAVO LIRA, B.: «El Derecho indiano después de la Independencia en América española: legislación y doctrina jurídica». En: Historia, núm. 19, 1984). Págs. 5-52.

CASARINO VITERBO, M.: Manual de Derecho procesal. Derecho procesal civil, III, $6^{\text {a }}$ ed. Actualizada. Editorial Jurídica de Chile, Santiago, 2005.

CASARINO VITERBO, M.: Manual de Derecho procesal. Derecho procesal civil, IV, $5^{\text {a }}$ ed. Editorial Jurídica de Chile, Santiago, 1997.

ESCRICHE Y MARTÍN, J.: Diccionario razonado de legislación y jurisprudencia. Nueva edición corregida por don Juan B. Guim. Librería de Rosa Bouret y Cía., París, 1852.

EYZAGUIRRE GUTIÉRREZ, J.: Historia del Derecho. $16^{\mathrm{a}}$ ed. Editorial Universitaria, Santiago, 2000.

FIGUEROA YÁVAR, J. A./MORGADO SAN MARTÍN, E.: Procedimientos civiles e incidentes. LegalPublishing/ThomsonReuters, Santiago, 2013.

GANDULFO RAMÍREZ, E.: «Sobre preclusiones procesales en el Derecho chileno en tiempo de reformas. Ensayo de una teoría general desde un enfoque valorativo jurídico». En: Revista Ius et Praxis, vol. 15, núm. 1, 2009. Págs. 121-189.

GARCÍA GOYENA, F./AGUIRRE, J.: Febrero, o Librería de jueces, abogados y escribanos. VI. I. Boix, Madrid,1842.

GUZMÁN BRITO, A., "La evolución jurídica", en SILVA VARGAS, F./ VARGAS CARIOLA, J.E. (eds.), Historia de Chile, Vol. 2: La búsqueda de un orden republicano. 1826-1881, Santiago, Ediciones UC, 2019, $1^{\text {a }}$ parte, pp. 183-224.

LAZO TORREALBA, S.: Los códigos chilenos anotados. Código de Procedimiento Civil (conforme con la edición oficial reformada de 1918). 
Orígenes, concordancias, jurisprudencia. Poblete Cruzat Hnos., Santiago, 1918.

LIRA ARGOMEDO, J. B.: Prontuario de los juicios o Tratado de procedimientos juicios y administrativos con arreglo a la legislación chilena, $5^{\text {a }}$ ed., I. Librería de Mariano Servat, Santiago,1895.

MUÑOZ MACHADO, S. (dir.): Diccionario panhispánico del español jurídico. Santillana, Barcelona, 2017.

RODRÍGUEZ PAPIC, I.: Procedimiento civil. Juicio ordinario de mayor cuantía. $6^{\mathrm{a}}$ ed. actualizada por Cristián Maturana Miquel. Editorial Jurídica de Chile, Santiago, 2003.

ROMERO SEGUEL, A.: Curso de Derecho procesal civil, III. Thomson Reuters, Santiago, 2015.

SÁEZ MARTÍN, J.: «Los elementos de la competencia jurisdiccional». En: Revista de Derecho de la Universidad Católica del Norte, vol. 22, núm. 1, 2015. Págs. 529-570.

SALVAT MONGUILLOT, M.: «Los prontuarios jurídicos chilenos en la primera mitad del siglo XIX (estudio y bibliografía)»: En Biblioteca del Congreso Nacional (ed.): Homenaje a Guillermo Feliú Cruz. Editorial Andrés Bello, Santiago, 1973. Págs. 905-918.

SALVAT MONGUILLOT, M.: «Sentido y forma de los prontuarios judiciales». En: Revista de Derecho Procesal, núm. 7, 1974. Págs. 69-73.

\section{Jurisprudencia citada.}

Corte Suprema, sentencia de 19 de marzo de 1986, Fallos del Mes, núm. 328,1986 , sent. $6^{\text {a }}$, p. 16.

Corte de Apelaciones de Santiago, sentencia de 3 de diciembre de 1903, Revista de Derecho y Jurisprudencia, tomo 1, 1903, sec. 2a, p. 197. 